\title{
Reflexiones sobre el reto de crecer y transformarse
}

\author{
Clemencia Martínez Londoño ${ }^{1}$
}

Martínez- Londoño, C. (2018). Reflexiones sobre el reto de crecer y transformarse. Revista Ocupación Humana, 18(2), 3-4. doi: https://doi.org/10.25214/25907816.225

Las organizaciones son entidades conformadas por individuos que las hacen tan dinámicas y cambiantes como sus integrantes y sus líderes lo permiten, quienes además, con sus argumentos y su hacer, dan o no cumplimiento a la misión que les ha sido encomendada. Al respecto, en una editorial como esta, escrita en 1997 por nuestra colega Alicia Trujillo Rojas, ella decía: "La Asociación Colombiana de Terapia Ocupacional [hoy Colegio Colombiano de Terapia Ocupacional] es y será lo que sus asociados quieran que ella sea" (p.II).

Nuevas visiones sobre estructuras organizacionales eficientes refieren la necesidad de reconocer y adaptarse a contextos renovados y dinámicos, disminuyendo así los riesgos de anquilosarse o de perder la esencia en el cumplimiento de sus objetivos. Plantean también estrategias tales como pasar de las relaciones jerárquicas al trabajo en equipo, y favorecer procesos de crecimiento y desarrollo personal y profesional que aseguren aprendizajes ajustados a las reales necesidades de la organización y generen genuinos liderazgos, todo ello para fortalecer y robustecer las instituciones.

Siendo necesario favorecer el desarrollo ordenado y progresivo del Colegio Colombiano de Terapia Ocupacional, contar con el Plan de Acción 2016 - 2026 (CСTO, 2016) ha marcado el punto de partida para iniciar la transformación de nuestra organización. En este marco, la puesta en funcionamiento de la Unidad de Registro Profesional de Terapia Ocupacional planteó la necesidad de

\footnotetext{
${ }^{1}$ Terapeuta Ocupacional. Presidenta del Consejo Directivo Nacional del Colegio Colombiano de Terapia Ocupacional 2018-2019. Bogotá, Colombia. presidencia@tocolombia.org
} 
generar una estructura administrativa y financiera que permitiera dar cumplimiento cabal y responsable a las funciones públicas delegadas por el Ministerio de Salud y Protección Social.

Más allá de esta situación, el Colegio tiene hoy una mayor visibilidad y un positivo reconocimiento, acompañados de una demanda importante de acciones pertinentes y oportunas orientadas a cumplir sus objetivos misionales, responder a sus estatutos, al desarrollo de lo proyectado en el Plan de Acción y a las inquietudes y necesidades particulares de sus colegiados.

Hoy, nuestro principal desafío es crecer y transformar la visión personal y profesional de cada uno de nosotros como parte de un colectivo, aceptando la importancia de nuestra participación en la valoración y la adecuación de los procesos administrativos, financieros y relacionales del Colegio. De igual forma, reconociendo nuestra capacidad de compromiso, disponibilidad, posibilidades, habilidades y experticias, aspectos fundamentales para la construcción colectiva de una organización estructuralmente dinámica, sostenible y viable, como le corresponde a nuestra profesión.

El camino lo construimos todos, colegiarnos y participar activamente con convicción, como colectivo, es también nuestro compromiso; la sumatoria de nuestras acciones hará cada día más sólida y eficiente a nuestra organización, el Colegio Colombiano de Terapia Ocupacional, y se reflejará en el posicionamiento profesional y político de la Terapia Ocupacional colombiana en la sociedad.

\section{Referencias}

Colegio Colombiano de Terapia Ocupacional -CCTO. Plan de acción 2016-2026. Disponible en: https:// www.tocolombia.org/elcolegio

Trujillo-Rojas, A. (1997). Editorial: poder asociativo. Revista Ocupación Humana, 7 (2), I-III. 